\title{
Uusia mahdollisuuksia kevätrypsin rikkakasvien torjuntaan
}

Heikki Jalli, Anna-Kaisa Ojantakanen²)

${ }^{1)}$ MTT Kasvinsuojelu, 31600 Jokioinen, heikki.jalli@mtt.fi

${ }^{2)}$ ProAgria Oulun Maaseutukeskus, Tutkimusasemantie 15, 92400Ruukki, anna-kaisa.ojantakanen@proagria.fi

\section{Tiivistelmä}

Rikkakasvien kemiallisen torjunnan mahdollisuuksia tutkittiin Jokioisilla osana "Rypsin viljelyvarmuuden parantaminen" -hanketta. Testasimme herbisidien biologista tehokkuutta ja käyttökelpoisuutta rypsinviljelyssä.

Rikkakasvit, jotka taimettuvat samanaikaisesti tai aikaisemmin kevätrypsin (Brassica rapa L. supsp. oleifera DC.) kanssa, kilpailevat kasvustossa ja heikentävät sadon laatua ja määrää. Rypsin rikkakasvien torjuntaa hankaloittaa sopivien herbisidien puute. Herbisidivalikoimasta puuttuvat etenkin rypsin ja rikkakasvien taimettumisen jälkeen käytettävät valmisteet, jolloin torjunnan tarpeen arviointi perustuu edellisten vuosien havaintoihin. Rypsin rikkakasvien torjuntaan rekisteröityjen herbisidien niukkuudesta johtuen kokeissa käytettiin tehoaineita, joiden soveltuvuudesta rypsille ei ollut varmuutta.

Kenttäkokeissa Jokioisilla tutkittiin vuosina 2002-2004 markkinoilla olevien herbisidien Super Treflanin (trifluraliini) ja Butisan S-valmisteen (metatsaklori) lisäksi uusia valmisteita. Uusia valmisteita olivat Devrinol- (napropamidi), Butisan TOP (metatsaklori+kvinmerakki), Raft 80 WG (oxadiargyl), Boxer (prosulfokarbi), Centium 36 (klomatsoni), Cirrus 36 CS (klomatsoni) ja Gratil (amidosulfuroni).

Koevuosien aikana markkinoille tuli napropamidi korvaamaan trifluraliinivalmisteita. Kokeissa olleista uusista tehoaineista metatsaklori+kvinmerakki on käyttökelpoinen. Lopuilla tutkituista tehoaineista rikkakasviteho on riittämätön, ja ne vioittavat rypsiä voimakkaasti, vaikkakaan vioitus ei aina merkinnyt sadon pienenemistä.

Kasvihuonekokeessa tutkittiin Super Treflanin ja Devrinolin vaikutusta rypsin ja viljan taimettumiseen ja alkukehitykseen. Kasvihuonekokeissa maavaikutteiset herbisidit hidastivat rypsin aikaista kehitystä, mutta myöhemmin erot tasoittuivat. Super Treflan 2,5 l/ha ja Devrinol 2,0 l/ha hidastivat kevätvehnän kehitystä.

Kenttäkokeessa Devrinolin kaksinkertainen käyttömäärä rypsillä ei vähentänyt rypsin sänkeen suorakylvetyn syysvehnän taimettumista, mutta heikensi vehnän versomista seuraavana kesänä.

\section{Asiasanat}

rypsi, rikkakasvit, rikkakasvien torjunta, herbisidit, trifluraliini, napropamidi, kvinmerakki, oxadiargyl, prosulfokarbi, klomatsoni 


\section{Johdanto}

Rypsin (Brassica rapa L. supsp. oleifera DC.) viljelyala oli kesällä 2005 yli 72000 hehtaaria (http://matilda.mmm.fi/ 2005). Viljelijät kokevat rypsin kylvön yhteydessä tehtävän herbisidikäsittelyn hankalaksi työvaiheeksi ja rikkakasvien torjunta tukeutuu usein viljelykierron muina vuosina tehtyihin kemiallisiin käsittelyihin. Onnistunut rikkakasvien säätely on tarpeen rypsisadon kehityksen ja sadon laadun varmentamiseksi. Rikkakasvit, jotka taimettuvat samanaikaisesti tai aikaisemmin kevätrypsin kanssa, kilpailevat kasvustossa ja heikentävät sadon laatua. Rypsin rikkakasvien torjuntaa hankaloittaa sopivien herbisidien puute. Herbisidivalikoimasta puuttuvat etenkin rypsin ja rikkakasvien taimettumisen jälkeen käytettävät valmisteet, jolloin torjunnan tarpeen arviointi perustuu edellisten vuosien havaintoihin.

Tutkimuksessa etsittiin uusia tehoaineita rypsin rikkakasvitorjuntaan, testattiin niiden biologinen tehoa ja käyttöominaisuuksia etenkin, kun trifluraliini-valmisteiden myyntilupa uhkaa loppua.

\section{Aineisto ja menetelmät}

Jokioisilla tutkittiin 2002-2004 kenttäkokeissa markkinoilla olevien herbisidien lisäksi uusia mahdollisesti käyttökelpoisia tehoaineita (Taulukko 1.). Kokeet kylvettiin kynnetylle koealalle maan kuivuttua kylvökuntoon. Viljellyt rypsilajikkeet olivat Kulta ja Valo ja siementä käytettiin 10 kg/ha.

Koejäsenistä napropamidille mainitaan (Tomlin 2000) yhdeksi käyttökohteeksi rypsi ja yleensä Brassicalajit, klomatsonille ja kvinmerakille vastaavasti rypsi. Lisäksi testattiin oxadiargylin) ja prosulfokarbin tehoa ja käyttökelpoisuutta käsittelyaikaa tarkentamalla ja käyttömäärää pienentämällä. Rypsin rikkakasvintorjunnassa amidosulfuronia on testattu Kanadassa Kasvihuonekokeessa käytetyt amidosulfuronimäärät olivat 0; 2,5; 5,0; 10,0 ja 15,0 g ai/ha ja ruiskutusajankohdat rypsin 2-3- ja 4-5- lehtiasteella(Kirkland 1995).

Ennen kylvöä käytettävät trifluraliini ja napropamidi ruiskutettiin joustopiikkiäkeellä tehtyjen muokkausten välillä. Kylvön jälkeen käsittelyaika eri tehoaineilla määräytyi rypsin ja rikkakasvien kehitysasteen mukaan. Herbisidit levitettiin kannettavalla koeruuturuiskulla käyttäen ruiskutemääränä 200 l/ha. Kunkin herbisidikäsittelyn jälkeen tehtiin noin kahden viikon ajan rypsin vioitushavaintoja. Kirpat ja rapsikuoriaiset torjuttiin tarpeen mukaan kaikilta koejäseniltä samanaikaisesti traktoriruiskulla.

Taulukko 1 Kokeissa olleet valmisteet, niiden tehoaineet, tehoainepitoisuudet.

\section{Käyttöaika ja valmiste}

A. Super Treflan

A. Super Treflan trifluraliini +

+ Devrinol

A. Devrinol

A. Devrinol

B. Butisan S

B. Butisan Top

B. Centium CS

B. Cirrus 36 CS

B. Boxer

C. Raft 80 WG

C. Raft 80 WG

C. Butisan $\mathrm{S}$

C. Butisan Top

C. Centium 36

C. Cirrus $36 \mathrm{CS}$

D. Gratil

D. Gratil

E. Gratil

D. Gratil
Tehoaine napropamidi napropamidi napropamidi metatsaklori metatsaklori kvinmerakki klomatsoni klomatsoni prosulfokarbi oxadiargyl oxadiargyl metatsaklori metatsaklori kviinmerakki klomatsoni klomatsoni amidosulfuroni amidosulfuroni amidosulfuroni amidosulfuroni

\begin{tabular}{|c|c|c|c|c|c|c|}
\hline g a.i./kg & \begin{tabular}{|c} 
Käyttöaik \\
Kylvö- \\
muokat- \\
taessa
\end{tabular} & $\begin{array}{l}\text { a I määrä } \\
\text { Ennen } \\
\text { rypsin } \\
\text { taimettu- } \\
\text { mista }\end{array}$ & $\begin{array}{c}\text { Rypsin } \\
2 \text { - } 4 \\
\text { lehtias- } \\
\text { teella } \\
\end{array}$ & $\begin{array}{c}\text { Rypsin } \\
3 \text { - } 4 \\
\text { lehtias- } \\
\text { teella } \\
\end{array}$ & $\begin{array}{c}\text { Rypsin } \\
4-5 \\
\text { lehtias- } \\
\text { teella } \\
\end{array}$ & Koevuosi \\
\hline $\begin{array}{c}480 \\
480+ \\
450 \\
450 \\
450 \\
500 \\
375 \\
125 \\
360 \\
360 \\
800 \\
800 \\
800 \\
500 \\
375 \\
125 \\
360 \\
360 \\
750 \\
750 \\
750 \\
750\end{array}$ & $\begin{array}{c}2 \mathrm{l} / \mathrm{ha} \\
1+1 \mathrm{l} / \mathrm{ha} \\
1 \mathrm{l} / \mathrm{ha} \\
2 \mathrm{l} / \mathrm{ha}\end{array}$ & $\begin{array}{c}2 \text { l/ha } \\
2 \text { l/ha } \\
\text { 0,25 I/ha } \\
0,25 \text { I/ha } \\
2 \text { l/ha }\end{array}$ & $\begin{array}{c}150 \mathrm{~g} / \mathrm{ha} \\
200 \mathrm{~g} / \mathrm{ha} \\
2 \mathrm{l} / \mathrm{ha} \\
2 \mathrm{l} / \mathrm{ha} \\
0.25 \mathrm{l} / \mathrm{ha} \\
0.25 \mathrm{l} / \mathrm{ha}\end{array}$ & $\begin{array}{c}7 \mathrm{~g} / \mathrm{ha} \\
13 \mathrm{~g} / \mathrm{ha} \\
20 \mathrm{~g} / \mathrm{ha}\end{array}$ & $7 \mathrm{~g} / \mathrm{ha}$ & $\begin{array}{c}-02,-03,-04 \\
-03 \\
-03 \\
-02,-03,-04 \\
-02,-03,-04 \\
-02,-03,-04 \\
-03 \\
-04 \\
-02 \\
-02 \\
-02 \\
-03,-04 \\
-03,-04 \\
\\
-03 \\
-04 \\
-03,-04 \\
-03,-04 \\
-03 \\
-04\end{array}$ \\
\hline
\end{tabular}


Noin kuuden viikon kuluttua viimeisestä herbisidikäsittelystä otettiin kaksi puolen neliömetrin rikkakasvinäytettä $24 \mathrm{~m}^{2}$ ruudun kummastakin päästä. Näytteestä lajiteltiin rikkakasvilajit erilleen, laskettiin kappalemäärät ja kuivauksen jälkeen mitattiin kasvien kuivapaino. Kasvuston tuleennuttua kasvusto puitiin ja satomäärä ja rypsin tuhannen siemenen paino mitattiin koejäsenittäin.

Kasvihuonekokeessa tutkittiin herbisidien vaikutusta rypsin ja viljan taimettumiseen ja alkukehitykseen. Astiakokeessa oli mukana kolme rypsin maavaikutteista tehoainetta trifluraliini, napropamidi) ja metatsaklori, joista jokaisesta oli neljä ruiskutusmäärää: puolitettu, normaalikäyttöohjeen mukainen, kaksinkertainen ja nelinkertainen annos sekä käsittelemätön kontrolli. Kokeessa oli rypsin lisäksi mukana myös kevätvehnä, jolla käytettiin vain herbisidien normaalia käyttömäärää. Taimettuneiden rypsien määrällä haluttiin tutkia, hidastavatko maavaikutteiset herbisidit rypsin taimettumista. Rypsin taimettumista seurattiin päivittäin laskemalla sirkkalehtiasteella olevat taimet.

Kahtena kenttäkoevuotena (2003 ja 2004) olleiden yhteisten koejäsenien rikkakasvi- ja satotulosten analyysissä SAS Mixed ohjelmalla aineistojen normaalisuus todettiin tutkimalla mallin antamia jäännöksiä graafisesti sen jälkeen, kun sekä rikkakasvikappale- että rikkakasvimassa-data oli neliöjuurimuunnettu.

\section{Tulokset ja tulosten tarkastelu}

Keväällä 2002 kuivuus ja halla haittasivat rypsin taimettumista savimaalla. Suuri rapsikuoriaismäärä heikensi kasvustoa insektisidien käytöstä huolimatta ja sato oli alle 500 kg/ha. Rypsin 2-4 lehtiasteella käytetyt oxadiargyl ja erityisesti prosulfokarbi vioittivat rypsiä. Herbisidivioituksen, hallan ja hyönteisten vioitusten erottaminen oli vaikeaa. Rikkakasveista $70 \%$ oli jauhosavikkaa, jota parhaiten torjui tirfluraliini. Kokeen epäonnistumisesta johtuen tuloksia ei esitetä.

Hyvissä käsittelyoloissa kesällä 2003 savi- ja hietamaalla rypsin taimettumisen jälkeen käytetyt herbisidit vioittivat viljelykasveja (kuva 2). Yleisimmät rikkakasvit olivat jauhosavikka (taulukko 2), johon tehosi parhaiten trifluraliini ja ennen rypsin taimettumista käytettyinä metatsaklori ja metatsaklori+kvinmerakki ja peltomatara, johon metatsaklori/kvinmerakki tehosi erittäin hyvin. Sato vaihteli 1300-1700 kg/ha (kuva 1).

Taulukko 2. Kahtena vuotena kokeissa olleiden herbisidikäsittelyjen rikkakasvitehot, kappaletta ja grammaa neliömetrillä.

$\begin{array}{lrrrrrrrrr}\text { Käsittelemätön } & & 23,5 & 2,3 & 16,9 & 4,3 & 1,7 & 0,3 & 112 & 13,4 \\ \text { A. Super Treflan } & 2 \text { l/ha } & 1,5 & 0,1 & 2,8 & 0,2 & 1,6 & 0,1 & 30 & 2,5 \\ \text { A. Devrinol } & 2 \text { l/ha } & 4,0 & 0,1 & 4,4 & 0,2 & 1,4 & 0,1 & 47 & 2,6 \\ \text { B. Butisan S } & 2 \text { I/ha } & 2,8 & 0,2 & 1,3 & 0,1 & 1,7 & 0,2 & 22 & 1,5 \\ \text { B. Butisan Top } & 2 \text { l/ha } & 4,4 & 0,3 & 3,8 & 0,4 & 1,3 & 0,2 & 25 & 1,6 \\ \text { C. Butisan S } & 2 \text { l/ha } & 5,9 & 0,4 & 5,2 & 0,1 & 1,6 & 0,1 & 34 & 2,0 \\ \text { C. Butisan Top } & 2 \text { l/ha } & 5,9 & 0,5 & 3,4 & 0,1 & 2,6 & 0,3 & 31 & 2,7 \\ \text { D. Gratil } & 7 \text { g/ha } & 21,0 & 2,9 & 10,8 & 3,4 & 3,7 & 0,7 & 100 & 13,4 \\ \text { D. Gratil } & 13 \text { g/ha } & 21,0 & 3,0 & 15,0 & 4,1 & 5,3 & 1,3 & 109 & 15,2\end{array}$

Kasvukaudella 2004 savi- ja hietamaalla yleisimmät rikkakasvit olivat pihatähtimö, jauhosavikka, peippi ja peltomatara. Paras rikkakasviteho saatiin ennen kylvöä käytetyillä maavaikutteisilla tehoaineilla. Rypsisato oli savella 1200-1450 kg/ha, hietamaalla sato (500-700 kg/ha) pilaantui kasvuston lakoontuessa ja pahkahomeen iskiessä sekä lintujen takia.

Yhdistettäessä rypsisadot vuosilta 2003 ja 2004 eri käsittelyjen sadot erosivat toisistaan 90 \% luotettavuudella. Hietamaan epäonnistumisesta johtuen koepaikkojen ja vuosien vaikutuksesta tuli erittäin merkitsevä (kuva 1). Analysoitaessa koepaikat erillään ei käsittelyjen vaikutus satoihin voimistunut. Rikkakasvien kokonaiskappalemäärät ja kokonaiskuiva-ainemassat erosivat erittäin merkitsevästi käsittelyjen välillä mutta vuosien vaikutus ei ollut merkitsevä. Rikkakasvien kappalemääriin koepaikalla eli maalajilla oli erittäin merkitsevä vaikutus. Hietamaalla herbisidit tehosivat savimaata paremmin. 


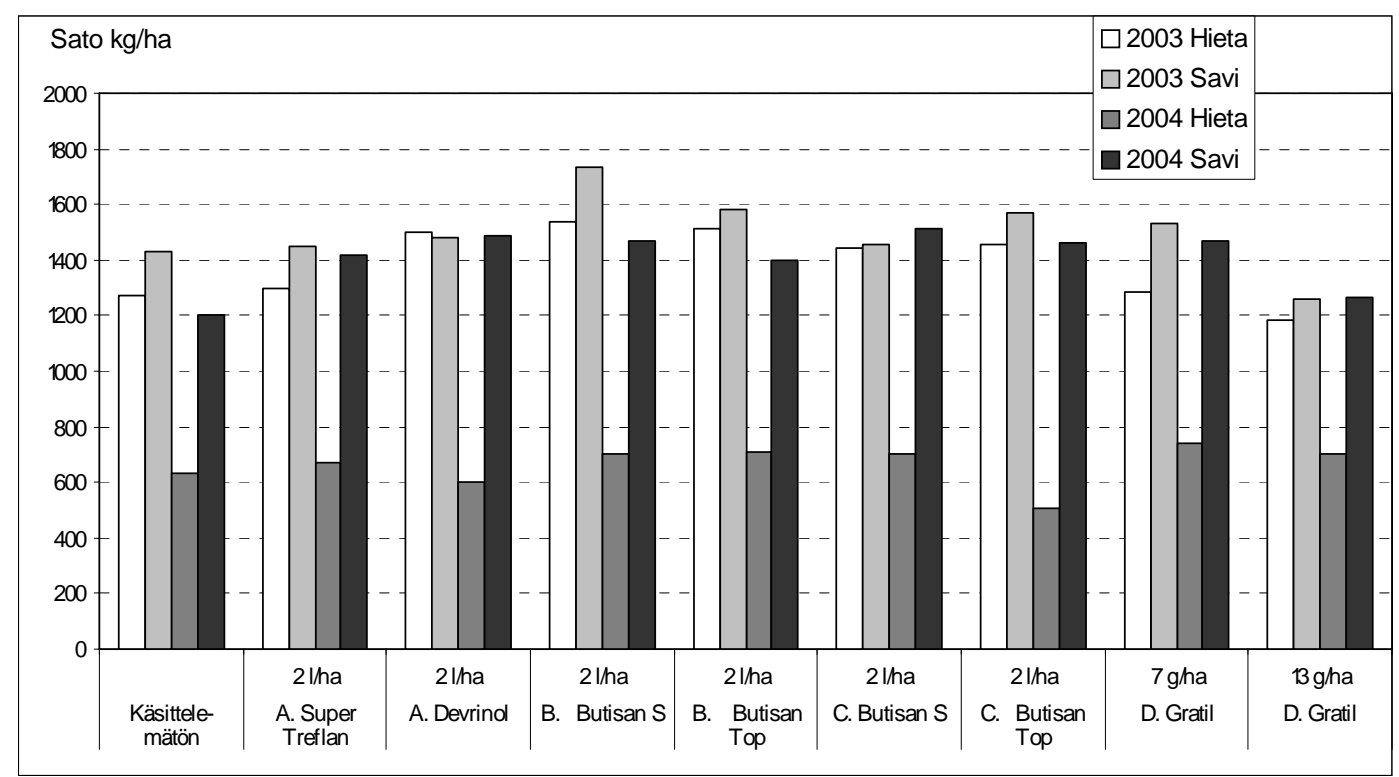

Kuva 1. Kahtena vuotena kokeissa olleiden herbisidikäsittelyjen satovaikutus.

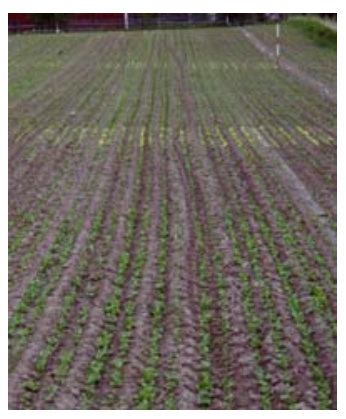

a)

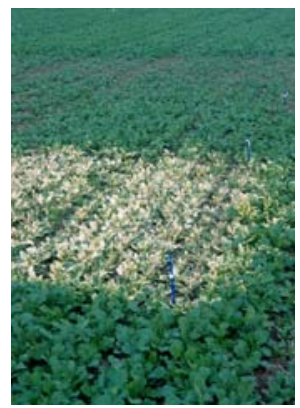

b)

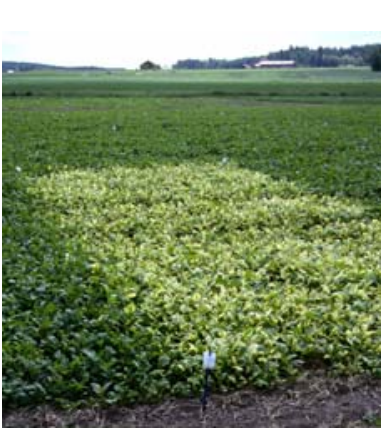

c)

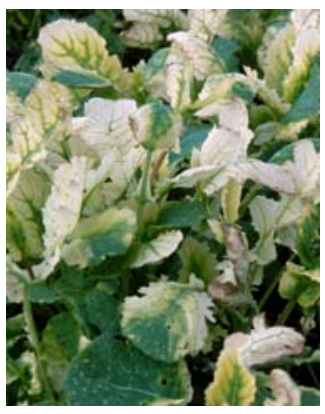

d)

Kuvat 2 a)-d). Kuvassa a) ennen vaaleaa klomatsonilla (Centium CS) käsiteltyä ruutua on taimettumisen jälkeisen metatsaklori -käsittelyn (Butisan-valmisteet) vioittamaa kasvustoa. Kuvassa b) vioittumattoman kasvuston viereisen kloroottisen klomatsoni-ruudun (Centium CS) jälkeen erottuu amidosulfuronin (Gratil) vioitus. c) 27.6.2003 alkaa jo uusi kasvu nousta klomatsoni-vioituksen alta. Lähikuva d) rypsin 2-3 lehtiasteella käytetyn klomatsonin vioituksesta. 
Kasvihuonekokeissa maavaikutteiset herbisidit hidastivat rypsin aikaista kehitystä, mutta myöhemmin erot tasoittuvat. Trifluraliini 1,2 kg/ha (Super Treflan 2,5 l/ha) ja napropamidi 0,9 kg/ha (Devrinol 2,0 l/ha) hidastivat kevätvehnän kehitystä (kuva 3) (Ojantakanen 2005).

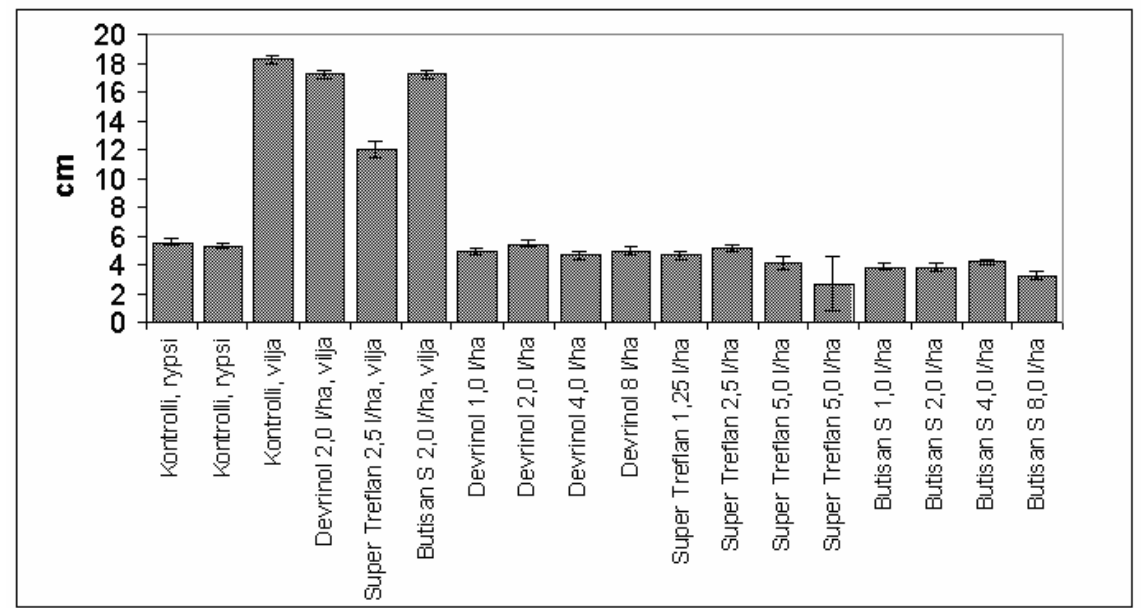

| Kuva 3. Herbisidin vaikutus rypsintaimien ja viljan oraiden pituuskasvuun. Oraiden keskipituudet koejäsenittäin kasvihuonekokeessa 14. heinäkuuta 2004 kaksi viikkoa kylvön jälkeen. Korjaus: koejäsen, jossa rypsin taimien pituuden hajonta on suurin pitää olla Super Treflan 10 l/ha.

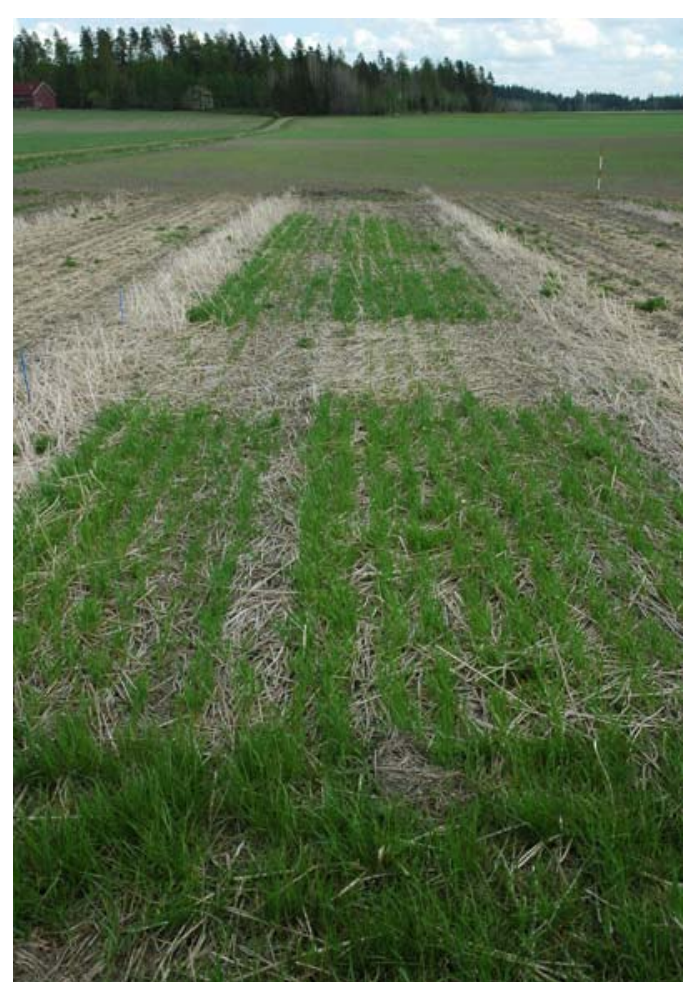

Kuva 4. Alue, jolta rikkakasvien torjuntaan on käytetty napropamidia $1,8 \mathrm{~kg} / \mathrm{ha}$ erottuu harvana.
Kenttäkokeessa napropamidin käyttömäärän kaksinkertaistaminen käyttöohjeenmukaisesta ei alentanut suorakylvetyn syysvehnän taimettumista.

Kuitenkin kaksinkertainen käyttömäärä (1,8 $\mathrm{kg} / \mathrm{ha}$ ) esti syysvehnän versominen seuraavana kesänä (kuva 4).

Koevuosien aikana markkinoille tuli napropamidi korvaamaan trifluraliinivalmisteita. Kokeissa olleista herbisideistä metatsaklori ja metatsaklori+kvinmerakki ovat käyttökelpoisia. Lopuilla valmisteista rikkakkasviteho on riittämätön ja ne vioittavat rypsiä herkästi, vaikkakaan vioitus ei aina merkitse sadon pienenemistä. 


\section{Johtopäätökset}

Kenttäkokeen tuloksista voidaan todeta, että ennen kylvöä käytetyt trifluraliini (Super Treflan) ja napropamidi (Devrinol) eivät vioita rypsiä ja torjuvat rikkakasvien massasta 80 \%. Metatsaklori (Butian S) ja metatsaklori+kvinmerak (Butisan Top) voivat kosteissa oloissa vioittaa rypsiä lievästi ja antavat 80 \% tehon rikkakasvien massaan. Klomatsoni (Cirrus 36 CS ja Centium CS), prosulfokarbi (Boxer) ja oxadiargyl (Raft 80 WG) eivät sovellu käytettäväksi rypsin viljelyssä vioittavuuden ja riittämättömän rikkakasvitehon takia. Kokeissa käytetyt pienet amidosulfuroniannokset (Gratil) aiheuttivat vioitusoireita, kuten Kirklandkin (1995) havaitsi. Rypsin kasvun heikkeneminen ja heikko rikkakasviteho suosivat rikkakasvien kasvua, vaikkakaan se ei kovin selvästi satotuloksiin heijastunut.

Kasvihuonekokeessa maavaikutteiset herbisidit hidastavat rypsin kehitystä taimettumisen alussa, mutta erot tasoittuvat kasvun edetessä.

Käyttöohjeeseen verrattuna kaksinkertainen Devrinolin (napropamidi). käyttömäärä ei haittaa suorakylvetyn syysvehnän taimettumista, mutta se estää syysvehnän versominen ja kasvun seuraavana kesänä. Käytännön torjuntatyössä tapahtuvan mahdollisen päällekkäinruiskutuksen vuoksi syysviljan suorakylvöön Devrinol-käsittelyn jälkeen on suhtauduttava varauksin.

Koevuosien aikana trifluraliinivalmisteiden rinnalle hyväksyttiin napropamidi. Kokeissa olleista herbisideistä metatsaklori ja metatsaklori+kvinmerakki ovat käyttökelpoisia, joten mahdollisuudet rypsin taimettumisen jälkeiseen rikkakasvien torjuntaan voivat hieman parantua.

\section{Kirjallisuus}

| http://matilda.mmm.fi/pls/portal30/rpportal.matilda_julkaisut.showfile?docid=619\&versio=1122563361\&fileid=1558 Päivitetty 28.7.2005

| Kirkland, K.J. 1995. HOE 075032 for wild mustard (Sinapis arvensis) control in canola (Brassica rapa). Weed Technology. 9: 541-545.

| Ojantakanen, A-K 2005 Metatsaklori-kvinmerak, klomatsoni ja amidosulfuronikevätrypsipeltojen leveälehtisten rikkakasvien kemiallisessa torjunnassa Pro gradu -tutkielma Helsinki, Helsingin Yliopisto Soveltavan biologian laitos. 77s.

| Tomlin, C.D.S. toim. 2000. The pesticide manual. Twelth edition. Farnham, British crop protection counsil.1250 s. ISBN 1901396126 